\title{
ON THE RELIABILITY OF MATHEMATICAL MODELLING OF CAPILLARY BARRIERS
}

\author{
JIRI MLS \& DAGMAR TRPKOSOVA \\ Charles University in Prague, Faculty of science, Albertov 6, 12843 Praha 2, Czech Republic. \\ Division of Chemistry of Fuel Cycle and Waste Management, Hlavní 130, 25068 Husinec-Řež, Czech Republic
}

\begin{abstract}
The problem of the reliability of capillary-barriers' modelling is studied making use of tipping trough measurements. In its first part, the article describes laboratory measurements of saturated hydraulic conductivities and retention curves of four materials of two different capillary barriers. Both the main branches of the retention curves were measured, and the unsaturated hydraulic conductivities and capacity functions were determined. The second part of the article describes numerical modelling of two tipping trough experiments. The obtained results are compared with the measured data. The comparison shows a good agreement that is presented and discussed. It is concluded that, in the case of capillary barrier materials, the laboratory measurements made on samples and the subsequent mathematical modelling can substitute for the tipping trough experiments.

Keywords: Capillary barrier, retention curve, hydraulic characteristics, suction apparatus, hydraulic conductivity, tipping trough.
\end{abstract}

\section{INTRODUCTION}

The capillary barrier is a simple device frequently used to cover landfills. It consists of two inclined layers: the overlying fine grained layer called the capillary layer and the underlying coarse grained layer called the capillary block. The capillary layer consists of finer material, usually a fine to medium grained sand, while the capillary block consists of significantly coarser material usually a uniform coarse-grained sand or fine-grained gravel.

The insulating effect of the barrier is based on the fact that, under sufficiently low values of pressure head, the hydraulic conductivity of the upper layer is significantly, at least one order, higher than that of the capillary block. The infiltrating water comes from above into the capillary layer and flows along it downwards rather than to cross the interface (the capillary interface) and to enter the capillary block, see e.g. Ross [1] or Abdolahzadeh et al. [2].

Several laboratory experiments testing two capillary barriers were carried out at the Ruhr University in Bochum. A large tipping trough containing the barriers was used for the experiments [3].

A measured time-dependent infiltration into the capillary layer was applied and the responding discharge from both layers of the tested barriers was measured as a function of time. The results made it possible to find out critical values of infiltration intensity and cumulative infiltration causing water flow through the capillary interface into the capillary block [3] and [4]. The tested barriers were built up of well-defined standard materials and, moreover, several physical characteristics of the materials were measured in Bochum.

Numerical simulations of water behaviour in capillary barriers are based on numerical solutions of the Richards equation describing water flow in unsaturated media. As the equation contains two unknown functions, the pressure head $\mathrm{h}$ and the water content 0 , it is necessary to make use of the material's soil-moisture retention curve either in the form

$$
h=h(\theta)
$$




$$
\begin{gathered}
\text { or } \\
\theta=\theta(\mathrm{h})
\end{gathered}
$$

in order to obtain a well-posed problem. The effect of retention curve hysteresis is usually neglected in such simulations, see e.g. [5-7]. However, Morris and Stormont [8] suggest that the hysteresis can affect predictions of flow and pressure conditions in capillary barriers. Trpkosova and Mls [9] studied the influence of the retention curve hysteresis on the water behaviour in capillary barriers and found that neglecting hysteresis in numerical simulations gives results that may overestimate the efficiency of the barrier and that the effect is proportional to the difference between the pressure head values of the inflection points of the main drying branch and the main wetting branch of the capillary-layer material.

The aim of the presented study was to test the reliability of mathematical modelling of capillary barriers under assumptions that laboratory measurements carried out just on samples of applied materials are available. That means, to carry out a set of laboratory measurements on samples of materials used in the tested capillary barrier, to determine the necessary hydraulic characteristics of the materials, to formulate the supposed experiments mathematically and eventually to solve the problems numerically. In order to test the agreement, materials of the capillary barriers tested in Bochum were utilized and the solved problems simulated the tipping trough experiments.

\section{PHYSICAL CHARACTERISTICS OF THE APPLIED SOILS}

Two different capillary barriers consisting of four different kinds of material were investigated during the experiments at Ruhr University Bochum. Several physical characteristics of the capillary barrier materials were determined in Bochum. Wohnlich [3] presents retention curve of one of the materials and grain-size curves, minimal and maximal compactness and chemistry of two materials.

As the numerical simulations of capillary barriers require complete sets of hydraulic characteristics of all applied materials [10], the required characteristics were determined at Charles University by means of laboratory measurements carried out on samples of the original materials.

Definitions of the studied materials are given below.

No. 1 - material of the capillary layer of the capillary barrier No. 1. The material is a product of the German company Tecklenborg. It is a heterogeneous sand originating in a river bed. Rough grains and calcareous layers were removed. According to Powers [11] classification, the sand belongs to the category rounded: both the corners and the edges of the grains are well rounded. The grain-size curve is shown in Fig. 1.

No. 2 - material of the capillary block of the capillary barrier No. 1. The material is a product of the German company G2. It is a homogeneous material of grain size from $2 \mathrm{~mm}$ to $8 \mathrm{~mm}$. According to Powers [11] classification, it belongs to the category subrounded: the corners of grains are well rounded, their edges are partly rounded. The grain-size curve is shown in Fig. 1. No. 3 - material of the capillary layer of the capillary barrier No. 2. The material is a homogeneous material of grain size from $0.4 \mathrm{~mm}$ to $1 \mathrm{~mm}$. According to Powers [11] classification, the sand belongs to the category rounded: both the corners and the edges of grains are well rounded. The grain-size curve is shown in Fig. 2.

No. 4 - material of the capillary block of the capillary barrier No. 2. The material is a homogeneous material of grain size from $2 \mathrm{~mm}$ to $7 \mathrm{~mm}$. According to Powers [11] classification, it belongs to the category not rounded. The grain-size curve is shown in Fig. 2. 


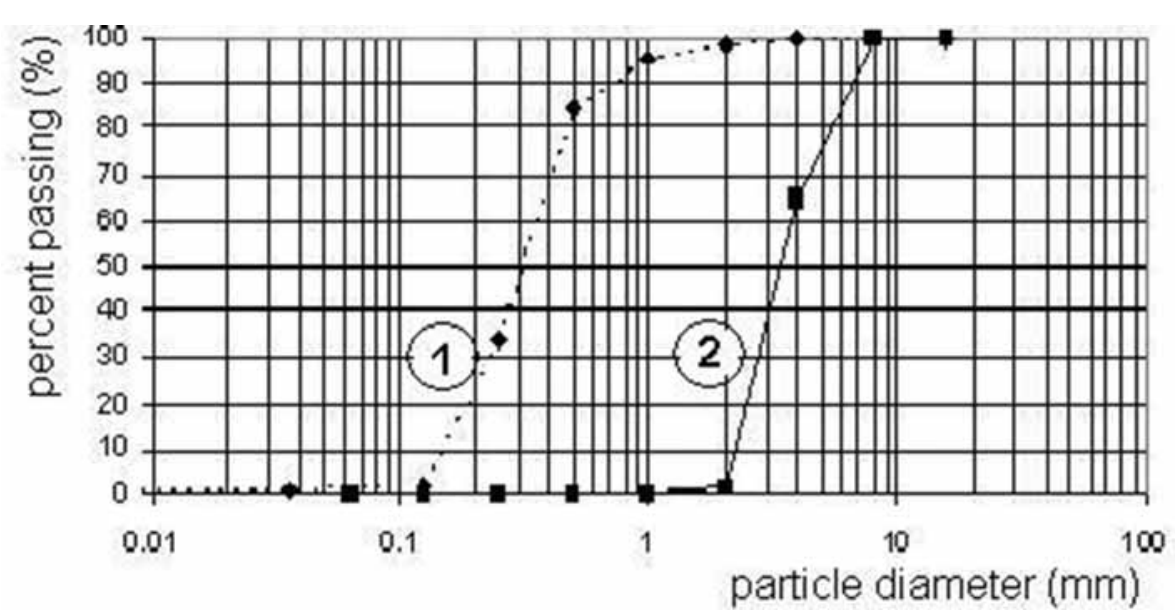

Figure 1: Grain-size curves of materials No.1 and No.2.

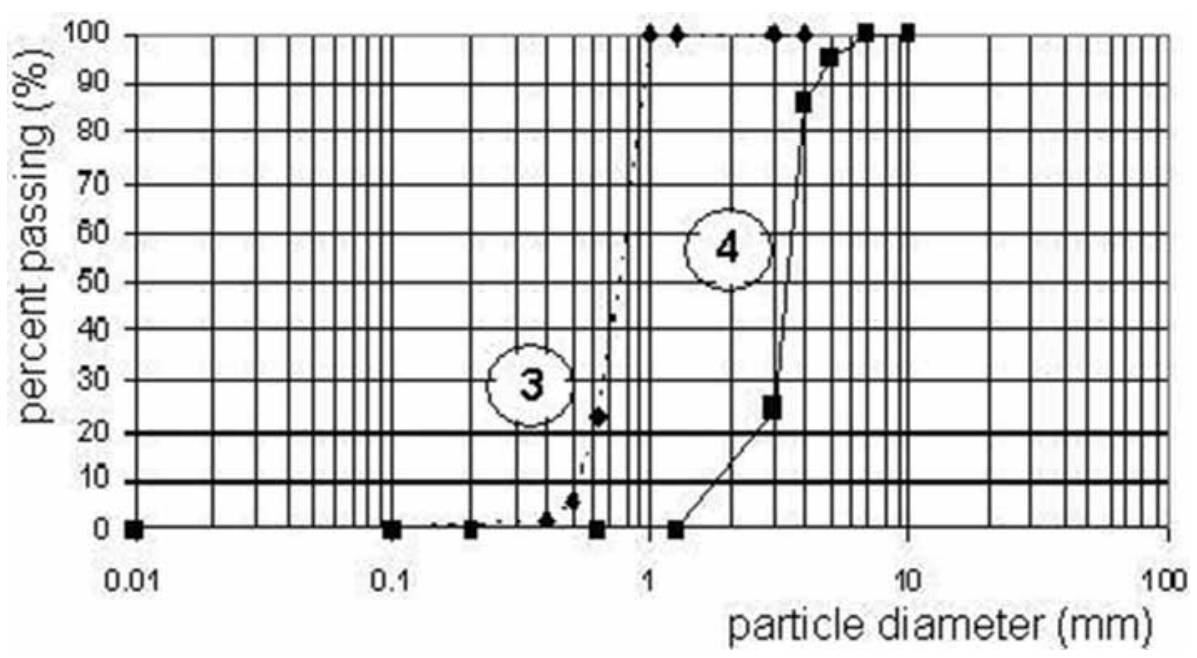

Figure 2: Grain-size curves of materials No. 3 and No. 4.

\section{LABORATORY MEASUREMENTS}

Most of the hydraulic characteristics required for numerical modelling of the capillary barriers can be determined from the soil-moisture retention curves. Wohnlich [3] presents the retention curve of material No. 1 obtained by a column test. The tension apparatus method was chosen for laboratory measurements of soil-moisture retention data by the authors. The design of the applied apparatus was that of Havlicek, J. and Myslivec [12]. The main drying branch and the main wetting branch of the retention curves were measured on each sample.

The tension apparatus is more convenient than the pressure-plate apparatus for the measured materials, i.e. sands. Moreover, the tension apparatus is suitable for the wetting branch measuring while the pressure-plate apparatus is usually utilized just for the drying branch measurements as it requires a special modification for this purpose [13]. Compared to the column test, the tension apparatus allows for finer distribution of measurement points at those parts of the curves where it is required by higher rate of change of the measured data. 
The particular points of the soil-moisture retention curves were measured in steps, controlled by setting the values of the pressure head. The increments ranged between $0.5 \mathrm{~cm}$ and $20.0 \mathrm{~cm}$ and were chosen to correspond to the change of the water content. Sets of 10-15 measured points served to define each branch of each retention curve.

During the main drying branch measurement, the sample of the measured material was converted from the saturated state into the residual-moisture state by gradual decreasing of the pressure head. Once the sample reached its residual state, the measurement of the wetting branch started. The minimum pressure head values applied to measured samples were as follows: material No. 1: $-200 \mathrm{~cm}$, material No. 2: $-35 \mathrm{~cm}$, material No. $3:-150 \mathrm{~cm}$ and material No. 4: $-17 \mathrm{~cm}$.

The amount of water in the apparatus was affected by evaporation. In order to determine the effect of this, free water table evaporation was measured as a function of time during the experiment. The obtained function was calibrated using the actual cumulative value measured as the difference between the water content of the sample at the beginning and at the end of the experiment and used to correct the measured retention curve data.

Besides the soil moisture retention data, the saturated hydraulic conductivities of the applied materials were measured in a permeameter working with a constant gradient of the hydraulic head. The samples used for the measurement of saturated hydraulic conductivity were cylindrical with the base of $5 \mathrm{~cm}$ in diameter and the average height of $7 \mathrm{~cm}$. Each sample was tested with 5 different values of the hydraulic head gradient. For each gradient, 5 measurements of the relation between the time and the cumulative outflow of water were carried out. The saturated hydraulic conductivities of the four tested materials were finally determined as mean values of the results of particular measurements.

As the tested materials allow the flow within the samples to easily reach non-Darcian regime, it was necessary to check the values of Reynolds number during the experiments in order to carry out the measurements at sufficiently low values of hydraulic-head gradients so that the Darcian flow was guaranteed. The obtained values of saturated hydraulic conductivities are presented in Table 2 (the results in this table are obtained from those presented in Table 1).

\section{HYDROMECHANICAL CHARACTERISTICS OF THE MATERIALS}

In order to simulate the capillary barriers numerically, it is necessary to know hydromechanical characteristics of their materials. As the capacity form of the Richards equation was used in our case, the retention curves and hydraulic conductivities were determined as functions of pressure head.

Flow of water in a capillary barrier, i.e. in the unsaturated zone, is governed by the Richards equation. Its capacity form reads

$$
C(h) \frac{\partial h}{\partial t}=\frac{\partial}{\partial x_{i}}\left(K(h) \frac{\partial h}{\partial x_{i}}+\delta_{i, 3} K(h)\right),
$$

where $t$ is the time, $x=\left(x_{1}, x_{2}, x_{3}\right)$ are the space coordinates with the $x 3$-axis oriented vertically upwards, $h$ is the pressure head, $C(h)$ is the capacity function, i.e. derivative of the retention function with respect to pressure head $h$,

$$
C(h)=\frac{\partial \theta}{\partial h}(h),
$$

and $K(h)$ is the unsaturated hydraulic conductivity. 
Table 1: Parameters of the tested materials obtained on individual samples.

\begin{tabular}{lccccccc}
\hline & $\theta_{r}$ & $\theta_{s}^{d}$ & $\theta_{s}^{w}$ & $a^{d}\left(\mathrm{~cm}^{1}\right)$ & $a^{w}\left(\mathrm{~cm}^{-1}\right)$ & $\mathrm{n}^{\mathrm{d}}$ & $\mathrm{n}^{\mathrm{w}}$ \\
\hline Material 1 & 0.07 & 0.37 & 0.31 & 0.026 & 0.036 & 9.41 & 7.35 \\
Material 1 & 0.03 & 0.34 & 0.31 & 0.025 & 0.034 & 5.75 & 4.05 \\
Material 1 & 0.03 & 0.34 & 0.32 & 0.024 & 0.036 & 8.22 & 4.33 \\
Material 1 & 0.02 & 0.34 & - & 0.025 & - & 6.17 & - \\
Material 2 & 0.05 & 0.40 & 0.40 & 0.268 & 0.321 & 4.57 & 4.60 \\
Material 2 & 0.09 & 0.42 & 0.42 & 0.276 & 0.300 & 4.84 & 4.68 \\
Material 2 & 0.08 & 0.43 & 0.42 & 0.296 & 0.338 & 4.27 & 3.71 \\
Material 2 & 0.02 & 0.40 & 0.39 & 0.291 & 0.339 & 4.38 & 3.70 \\
Material 2 & 0.11 & 0.40 & - & 0.283 & - & 5.42 & - \\
Material 2 & 0.04 & 0.39 & - & 0.300 & - & 3.87 & - \\
Material 3 & 0.03 & 0.40 & 0.38 & 0.058 & 0.082 & 5.14 & 3.71 \\
Material 3 & 0.02 & 0.43 & 0.38 & 0.065 & 0.097 & 4.54 & 2.95 \\
Material 3 & 0.01 & 0.41 & 0.37 & 0.064 & 0.094 & 3.68 & 3.03 \\
Material 4 & 0.03 & 0.40 & 0.39 & 0.211 & 0.267 & 3.41 & 4.47 \\
Material 4 & 0.04 & 0.39 & 0.39 & 0.235 & 0.270 & 4.85 & 4.19 \\
Material 4 & 0.04 & 0.39 & 0.38 & 0.250 & 0.330 & 5.71 & 3.49 \\
Material 4 & 0.09 & 0.40 & - & 0.285 & - & 3.79 & - \\
Material 4 & 0.08 & 0.40 & - & 0.257 & - & 4.74 & - \\
\hline
\end{tabular}

To define the retention function in Equation (1), the van Genuchten [14] formula was chosen in this paper

$$
\theta(h)=\theta_{r}+\frac{\theta_{s}-\theta_{r}}{\left(1+(-\alpha h)^{n}\right)^{m}},
$$

where $\mathrm{h}<0, \alpha, m, n, \theta s$ and $\theta r$ are the parameters, $a>0, n>1, \mathrm{~m}=1-1 / \mathrm{n}$. While the water content at saturation and the residual water content, parameters $\theta_{\mathrm{s}}$ and $\theta_{\mathrm{r}}$, were measured directly on each sample, it was necessary to determine the parameters $a$ and $n$ as constants giving the best fit of function (2) to the measured soil-moisture retention data. To do this, the computer code RETC [15] was used. The set of parameters $\theta_{\mathrm{s}}, \theta_{\mathrm{r}}, \alpha, m, n$ was determined for every sample and every branch of the retention curve. The results are presented in Table 1.

The voids in the table denote the experiments at which the hydraulic contact was lost and the measured set of data could not be completed.

The statistical pore-size distribution model by Mualem [16] was used to define the unsaturated hydraulic conductivity $K(h)$ in the form

$$
K(\theta)=K_{s} \sqrt{\frac{\theta-\theta_{r}}{\theta_{s}-\theta_{r}}}\left(\frac{1-F(\theta)}{1-F\left(\theta_{s}\right)}\right)^{2},
$$

where $K s$ is the measured saturated hydraulic conductivity, the function $F$ is given by 
Table 2: Resulting parameters of the tested materials.

\begin{tabular}{lcccccccc}
\hline & $\theta_{r}$ & $\theta_{s}^{d}$ & $\theta_{s}^{w}$ & $a^{d}\left(\mathrm{~cm}^{-1}\right)$ & $a^{w}\left(\mathrm{~cm}^{-1}\right)$ & $n^{d}$ & $n^{w}$ & $K_{s}(\mathrm{~m} / \mathrm{s})$ \\
\hline Material 1 & 0.04 & 0.35 & 0.31 & 0.03 & 0.04 & 7.39 & 5.24 & $1.18 \mathrm{e}-4$ \\
Material 2 & 0.07 & 0.41 & 0.41 & 0.29 & 0.32 & 4.56 & 4.17 & $2.25 \mathrm{e}-3$ \\
Material 3 & 0.02 & 0.41 & 0.38 & 0.06 & 0.09 & 4.45 & 3.23 & $7.63 \mathrm{e}-4$ \\
Material 4 & 0.06 & 0.40 & 0.39 & 0.25 & 0.29 & 4.50 & 4.05 & $1.72 \mathrm{e}-3$ \\
\hline
\end{tabular}

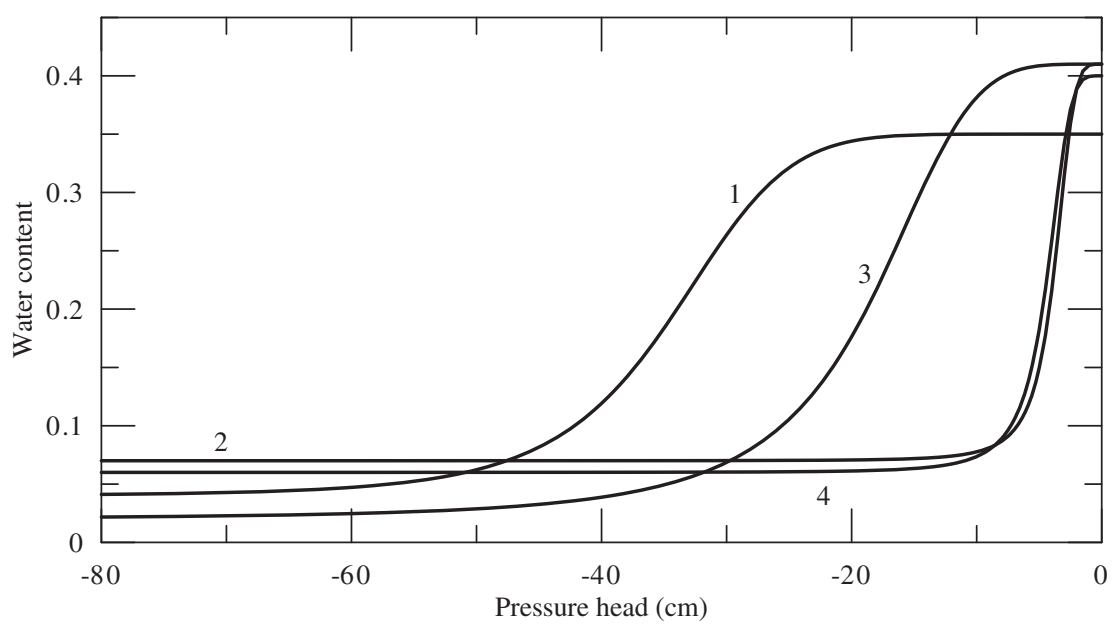

Figure 3: Soil-moisture retention curves of the four materials. The curves numbers are those of the materials.

$$
F(\theta)=\left(1-\left(\frac{\theta-\theta_{r}}{\theta_{s}-\theta_{r}}\right)^{1 / m}\right)^{m},
$$

and $\theta_{s}, \theta_{r}$ and $\mathrm{m}$ are the above defined parameters. The inverse form of Equation (2) was used to convert the function $K(\theta)$ to function $K(h)$.

The set of data obtained on the samples was used to define the resulting hydraulic parameters of the four materials, see Table 2.

Retention curves, the main drying branches and the main wetting branches, of the four materials are depicted in Fig. 3, and their unsaturated hydraulic conductivities are depicted in Fig. 4.

\section{NUMERICAL SIMULATIONS OF THE TIPPING TROUGH EXPERIMENTS}

The tipping trough experiments were mathematically formulated as two-dimensional flow of water in unsaturated zone. It was supposed that the materials of the capillary layer and the capillary block were homogeneous and isotropic and that their hydromechanical characteristics were defined by the parameters obtained by measuring on samples and presented in Table 2. 


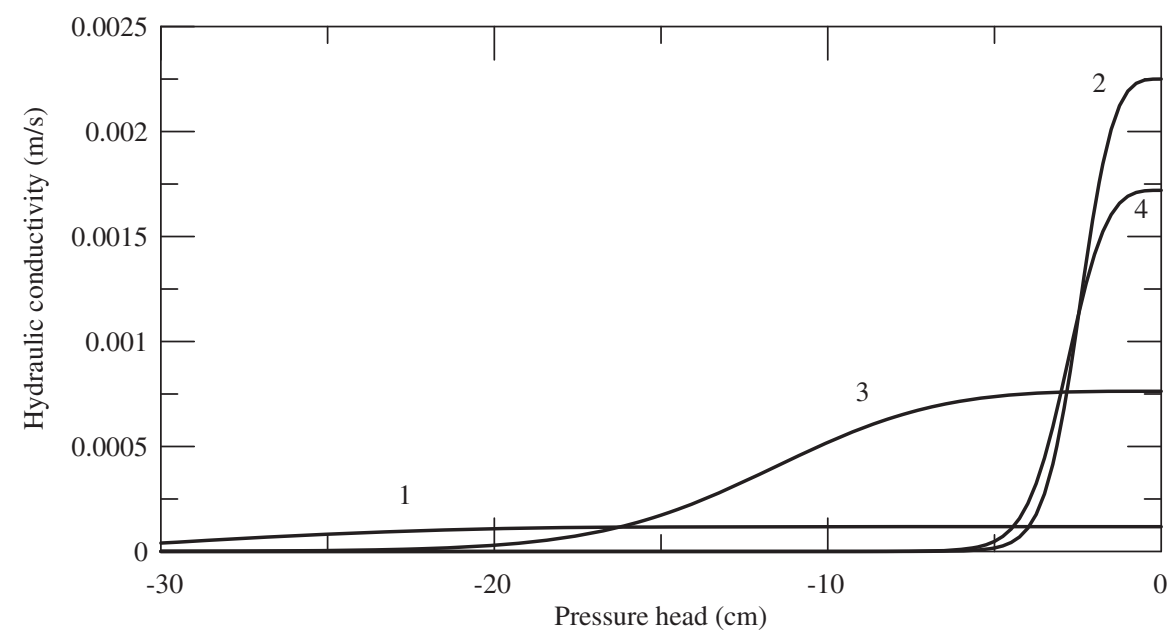

Figure 4: Hydraulic conductivities of the four materials. The curves are numbered according to the materials numbering.

The imposed boundary conditions reflected the known conditions of the tipping trough experiments. Particularly the time-dependent condition prescribed at the upper surface of the capillary layer was of the Neumann type and was given by the known rate of irrigation. The discharge from the layers was measured separately. It was modelled by the seepage face conditions at the particular parts of the boundary which were surrounded by isolated parts (no flow conditions) exactly as it was made at the places where the discharge from the layers was measured in the tipping trough.

It was supposed that the initial distribution of water in the layers was homogeneous and, in view of this assumption, an estimated constant value of water content was prescribed as the initial condition in each layer. The simulations started with water content values of 0.119 and 0.070 for the capillary layer and the capillary block of the first barrier, respectively.

The hysteresis of the retention curves was neglected and the main wetting branches were used as the retention curves in the numerical models. The choice of the main wetting branches was based on results of the paper by Trpkosova and Mls [9] where it was shown that the efficiency of capillary barriers may be overestimated when just the main drying branches are utilized. As the measured discharge from the capillary block was nonzero from the very beginning of the experiments with the second barrier, these experiments were not modelled numerically and only the experiments carried out with the first capillary barrier were utilized in this study.

The length of the tipping trough was $6 \mathrm{~m}$, its incline with respect to horizontal plane was $11.3^{\circ}$, and the depths of the capillary block and the capillary layer were $20 \mathrm{~cm}$ and $40 \mathrm{~cm}$, respectively.

The program S2D_dual [17] was chosen for the problem solution. The code solves the capacity form (1) of the Richards equation using the finite element method. The required mesh of triangular elements was created using the MLGS code of the Menhart package [18]. The mesh applied in the numerical simulations had over 3000 elements, the typical distance of neighbouring nodes was about $5 \mathrm{~cm}$. Because of the discontinuity of the material parameters at the capillary interface, it was necessary to make the mesh much denser here in order to 


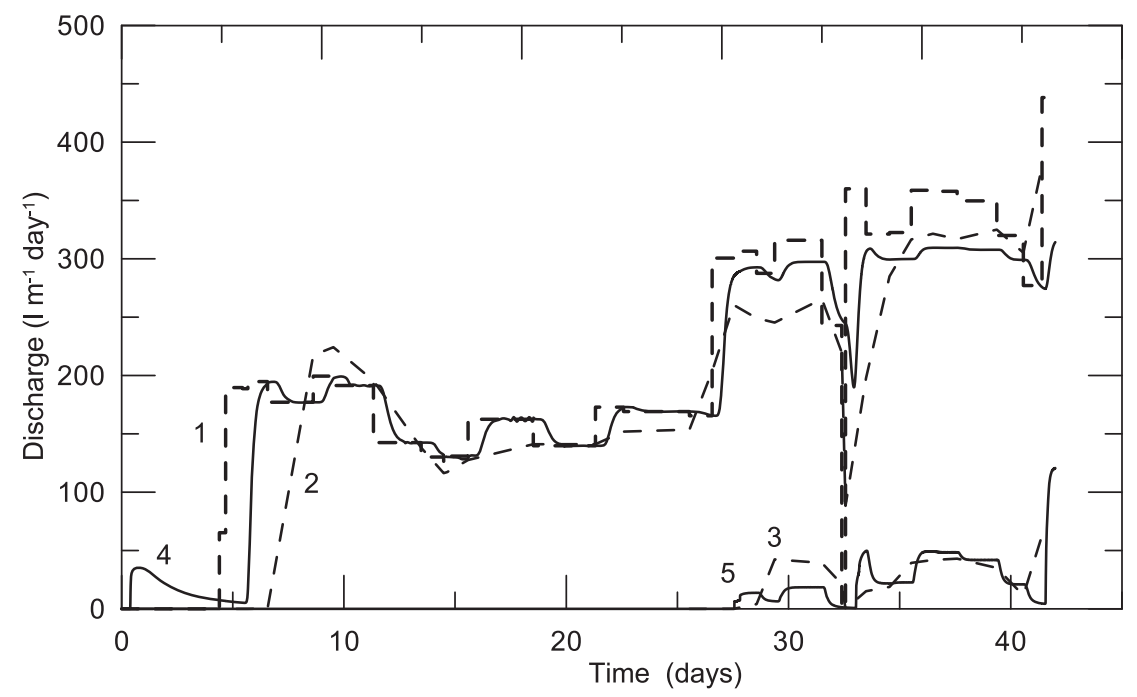

Figure 5: Capillary barrier No. 1, the first experiment. Comparison of numerical solution (solid lines) and tipping trough measurements (dashed lines).

reach sufficient accuracy of the solution. The distances of nodes in the region of the capillary interface shrank down to few millimetres.

The obtained results of the numerical modelling are presented in Figs 5 and 6 .

Overall five functions are depicted in each figure. The dashed lines present results measured during the tipping trough experiments in Bochum. The functions are numbered: 1 is the irrigation, 2 is the discharge from the capillary layer and 3 is the discharge from the capillary block. The solid lines present the numerical results obtained by the authors: 4 is the discharge from the capillary layer and 5 is the discharge from the capillary block. The figures demonstrate a very good agreement between the measured and computed results. Particularly, their agreement in time and in values of the discharge from the capillary block suggests that the presented approach of numerical modelling based on laboratory measurements on samples can give reliable results.

\section{DISCUSSION AND CONCLUSIONS}

Two different tipping trough experiments with the first capillary barrier were repeated numerically. The numerical values of the discharges from the capillary layer and the capillary block are in a good accordance with the corresponding measurements when compared as functions of time.

It can be seen from the comparison that numerical results are more sensitive to changes of the rate of infiltration, i.e. the time needed for response is shorter and the response is more significant, than was found at the measured values. This can be considered as the most important difference between the results of the mathematical model and the measurements.

The relatively big differences at the beginning of both the experiments resulted evidently from the imposed initial condition. A proper space distribution of the water content could lead to better results than the applied assumption of the water content homogeneity.

Another significant disagreement can be found between the curves of discharge from the capillary layer from the 15 th to the 27 th day of the second experiment. In this case, however, 


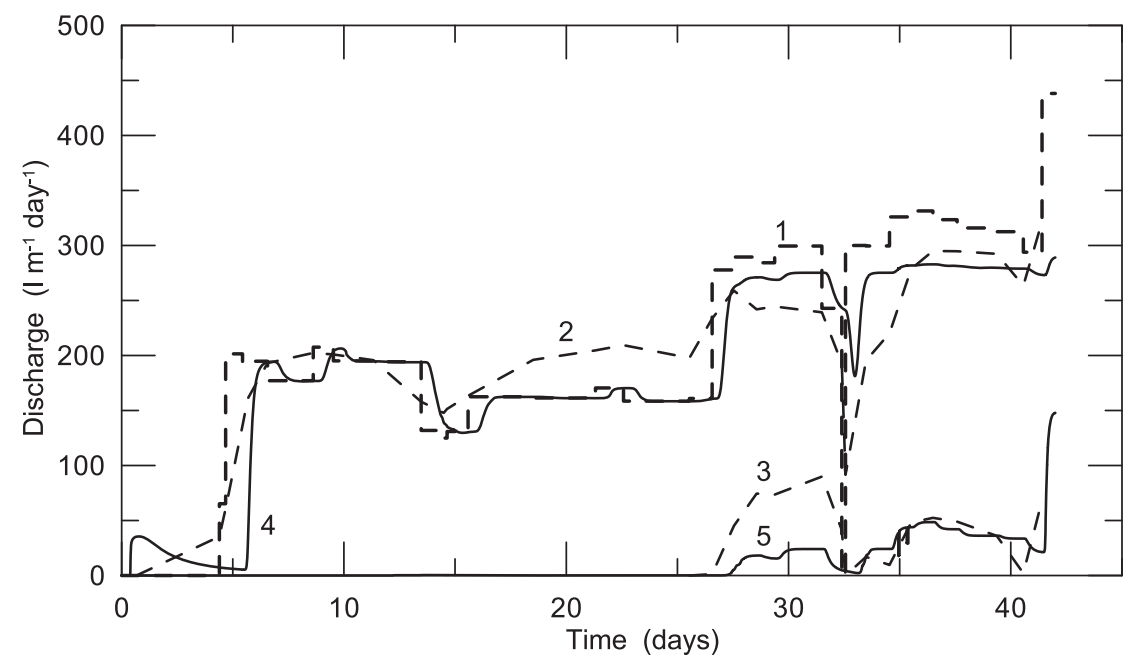

Figure 6: Capillary barrier No. 1, the second experiment. Comparison of numerical solution (solid lines) and tipping trough measurements (dashed lines).

one can be almost certain that the laboratory measured values are too big to reflect the imposed irrigation.

It should be stressed that the parameters of the model were not calibrated to the tipping trough measurements. The presented agreement between the measured and computed data was achieved using parameters measured in the tension apparatus and in the permeameter. The results of this study suggest that, in the case of materials convenient for capillary barriers, the hydromechanical characteristics based on laboratory measurements of retention curves and saturated hydraulic conductivities carried out on samples can serve as sufficiently reliable parameters of a numerical model of the corresponding capillary barrier. In this way the measurements on samples of the chosen materials and subsequent numerical modelling can serve as a substitute for tipping trough measurements.

\section{ACKNOWLEDGMENT}

This article is based upon work supported by the Ministry of Education of the Czech Republic under grant no. MSM0021620855.

\section{REFERENCES}

[1] Ross, B., The diversion capacity of capillary barriers. Water Resources Research, 26(10), pp. 2625-2629, 1990. doi: http://dx.doi.org/10.1029/WR026i010p02625

[2] Abdolahzadeh, A.M., Vachon, B.L. \& Cabral, A.R., Evaluation of the effectiveness of a cover with capillary barrier effect to control percolation into a waste disposal facility. Canadian Geotechnical Journal, 48(7), pp. 996-1009, 2011. doi: http://dx.doi. org/10.1139/t11-017

[3] Wohnlich, S., Untersuchungsbericht-Dichtigkeitsnachweis der Kombikapillardichtung (KKD). 3. Kipprinnenversuch, Bochum, 2006.

[4] Wohnlich, S. \& Bitomski, K., Kombi-Kapillar-Dichtungs-Systeme zur Obelflchenabdichtung von Deponien und Altlasten. 22. Fachtagung Die sichere Deponie, Sicherung von Deponien und Altlasten mit Kunststoffen, Wurzburg, 2006. 
[5] Oldenburg, C.M. \& Pruess, K., On numerical modeling of capillary barriers. WaterResources Research, 29(4), pp. 1045-1056, 1993. doi: http://dx.doi.org/10.1029/92 WR02875

[6] Webb, S.W., Generalization of Ross' tilted capillary barrier diversion formula for different two-phase characteristic curves. Water Resources Research, 33(8), pp. 1855-1859, 1997. doi: http://dx.doi.org/10.1029/97WR01231

[7] Trpkosova, D. \& Mls, J., The influence of artificial sealing on the capillary barrier's function. Waste Management, 30(1), pp. 125-131, 2010. doi: http://dx.doi.org/10.1016/j. wasman.2009.09.029

[8] Morris, C.E. \& Stormont, J.C., Evaluation of numerical simulations of capillary barrier field tests. Geotechnical and Geological Engineering, 16, pp. 201-213, 1998. doi: http://dx.doi.org/10.1023/A:1008853710339

[9] Trpkosova, D. \& Mls, J., Efficiency of capillary barriers in relation to retention curves data. Acta Geodynamica et Geomaterialia, 7(2), pp. 201-207, 2010.

[10] Trpkosova, D. \& Mls, J., Hydraulic characteristics of capillary barrier in relation to its efficiency. Acta Hydrologica Slovaca, 9(2), pp. 170-178, 2008. (in Czech).

[11] Powers, M.C., A new roundness scale for sedimentary particles. Journal of Sedimentary Research, 23(2), pp. 117-119, 1953.

[12] Havllcek, J. \& Myslivec, A., The Influence of Saturation and Stratification on the Shearing Properties of Certain Soils. In Proceedings 6th Int. Conf. Soil and Mech. Found. Engineering, 1, pp. 235-239. University of Toronto Press, 1965.

[13] Kuraz, V., Kucerova, A. \& Kuraz, M., The use of genetic algorithms for retentioncurves approximation. In Proceedings of the Conference Days of Soil Physics, Velke Bilovice, 2003. (in Czech).

[14] van Genuchten, M.T., A closed-form equation for predicting the hydraulic conductivity of unsaturated soils. Soil Science Society of America Journal, 44(5), pp. 892-898, 1980. doi: http://dx.doi.org/10.2136/sssaj1980.03615995004400050002x

[15] van Genuchten, M.T., Leu, F.J. \& Yates, S.R., The RETC Code for Quantifying the Hydraulic Functions of Unsaturated Soils, EPA: California, 1991.

[16] Mualem, Y., New model for predicting hydraulic conductivity of unsaturated porousmedia. Water Resources Research, 12(3), pp. 513-522, 1976. doi: http://dx.doi.org/ 10.1029/WR012i003p00513

[17] Vogel, T., Documentation of the S2D Code - Version 2.0, CTU Praha, 1999. (internal).

[18] Mls, J., Description of the M.GS.vOl code. UK Praha, 2002. (in Czech, unpublished). 